\title{
Neo-revascularization as the potential treatment for patient suffering from pulmonary arterial hypertension (myth or reality)
}

\author{
Aris Lacis 1, *, Inguna Lubaua ${ }^{2}$, Valts Ozolins', Eriks Jekabsons ${ }^{3}$, Andis Lacis ${ }^{2}$, Mara Ratniece ${ }^{3}$, \\ Andrejs Erglis ${ }^{4}$ \\ ${ }^{1}$ Clinic of Pediatric Cardiology and Cardiac Surgery, University Children Hospital, Riga, Latvia \\ ${ }^{2}$ Riga Stradins University, Riga, Latvia \\ ${ }^{3}$ Pauls Stradins Clinical University Hospital, Riga, Latvia \\ ${ }^{4}$ Latvian Institute of Cardiology, Riga, Latvia
}

\section{Email address:}

aris.lacis@apollo.lv(A. Lacis), inguna.lubaua@rsu.lv(I. Lubaua)

\section{To cite this article:}

Aris Lacis, Inguna Lubaua, Valts Ozolins, Eriks Jekabsons, Andis Lacis, Mara Ratniece, Andrejs Ergli. Neo-Revascularization as the Potential Treatment for Patient Suffering from Pulmonary Arterial Hypertension (Myth or Reality). Clinical Medicine Research.

Vol. 2, No. 3, 2013, pp. 32-36. doi: 10.11648/j.cmr.20130203.13

\begin{abstract}
Pulmonary arterial hypertension (APAH, IPAH) is a devastating, progressive disease with increasingly debilitating symptoms [1,2].Intrapulmonary delivery of autologous stem cells could be beneficial for pathogenetic treatment for patients with severe pulmonary arterial hypertension. Two patients with severe pulmonary artery hypertension received intrapulmonary autologous mesenchymal (mononuclear) stem cell transplantation and stem cell transplantation in pulmonary arteries. Patients were examined by scintigraphy of lungs during the periods 12, 14 and 27 months after stem cell transplantation. We find out that perfusion in all lung segments were improved after 14 and 27 months.
\end{abstract}

Keywords: Stem Cell Transplantation, Intrapulmonary Delivery, Pulmonary Artery Hypertension, Pulmonary Vascular Resistance

\section{Introduction}

Pathophysiology of pulmonary hypertension includes systemic inflammation process as pneumonia or chronic obstructive pulmonary disease (COPD), systemic diseases - sclerodermia, rheumatic fever, congenital heart diseases or pulmonary artery pathology.

As a result of these changes patients have compensatory right chamber hypertrophy and dilatation of chambers and leads to heart failure. It is a progressive disease with increasingly debilitating symptoms. Right ventricle hypertrophy is tolerant for pulmonary hypertension without symptoms until $50 \mathrm{mmHg}[1,2]$. Increased pulmonary vascular resistance results in extensive heart structural changes, limits patients exercise capacity [2].

Mechanism of pathogenesis in pulmonary artery hypertension is changes in pulmonary parenchyma or in pulmonary arteries (see picture 1).

The majority of children are treated with disease-target therapies, these include intravenous epoprostend [3] (the only drug for children tested in a placebo-controlled trial) other prostanoids, bosentan [4] and sildenafil. Survival is better in children given combination therapy than in those given monotherapy. Planning the stage treatment for patients with dilatation cardiomyopathy include early diagnostic. Currant treatment strategy is medical treatment and after disease progression - ventricle assist device and heart transplantation $[5,6]$.

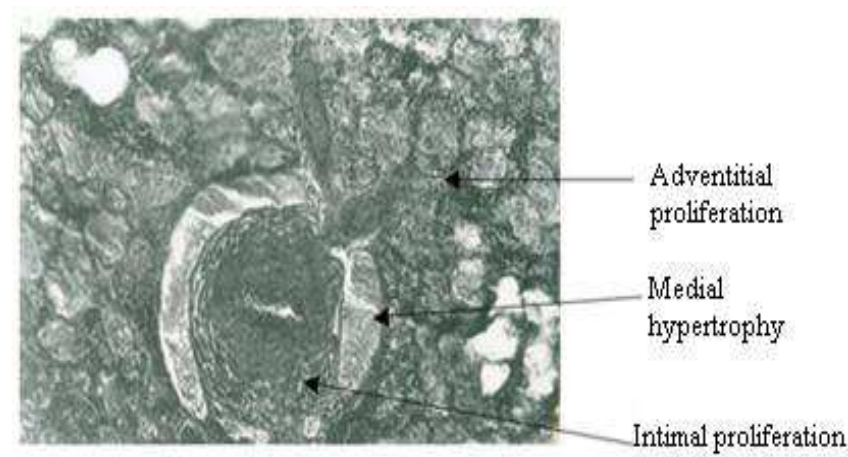

Picture 1. Intimal and medial disruption and hypertrophy in terminal bronchial arteriole. 
Current therapies for pulmonary arterial hypertension slow down disease progression but are not curative. New approaches to treatment will be the only means to benefit patients.

\section{Patients and Methods}

Possibility for revascularization of pulmonary arterial blood vessels in patients suffering from severe forms of pulmonary arterial hypertension after intrapulmonary delivered autologous mesenchymal (mononuclear) stem cells have been studied in two (2) patients aged 9 and 15 years (body weight 58 and $37 \mathrm{~kg}$ ) suffered from uncorrected (not repaired) congenital heart defects (VSD) complicated with severe pulmonary arterial hypertension (WHO functional class II and III) and PVR/SVR - 1/1, 3.

Treatments approved for pulmonary arterial hypertension include: Sildenifil, Accupro, Aspirin, Propanolol. Clinical investigations include routine Eho, ECG, Chest X-ray, complex intracardial investigation including angiocardiography.

Local independent ethics committee approved the procedure and protocol. Written informed consent was obtained from parents.

One of patients received transcatheter stem cell infusion in both (left and right) pulmonary arteries and stem cells substrate delivery intrapulmonary (directly in pulmonary parenchyma upon and lower lobe of right lung) using transcutaneous approach under general anesthesia (see pictures 2 and 3). Another patient received transcatheter stem cell infusion in left pulmonary artery and stem cell substrate in pulmonary parenchyma upon and lower lobe of right lung (see picture 4 ).

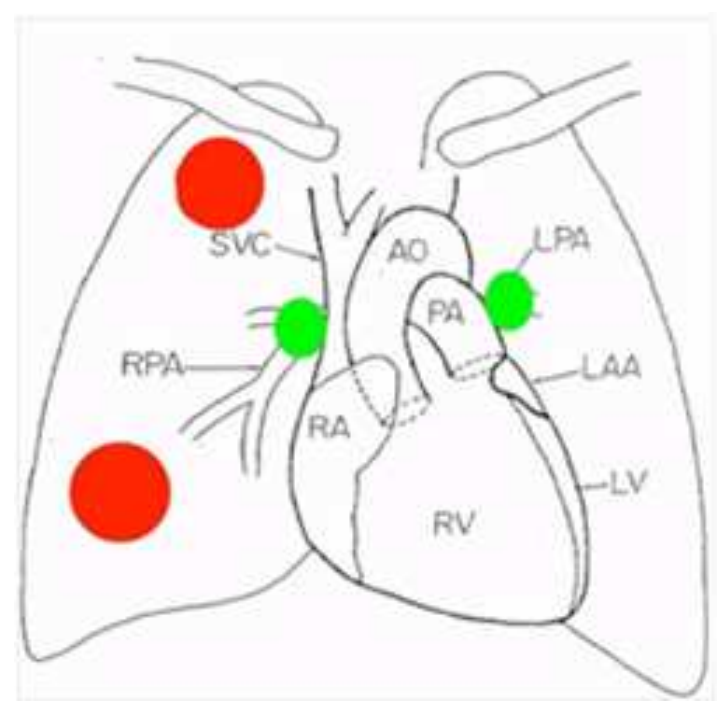

Picture 2. Schematic representation of stem cells delivery area.

Green color - stem cell transplantation in pulmonary arteries. Red color - stem cell transplantation intrapulmonary.

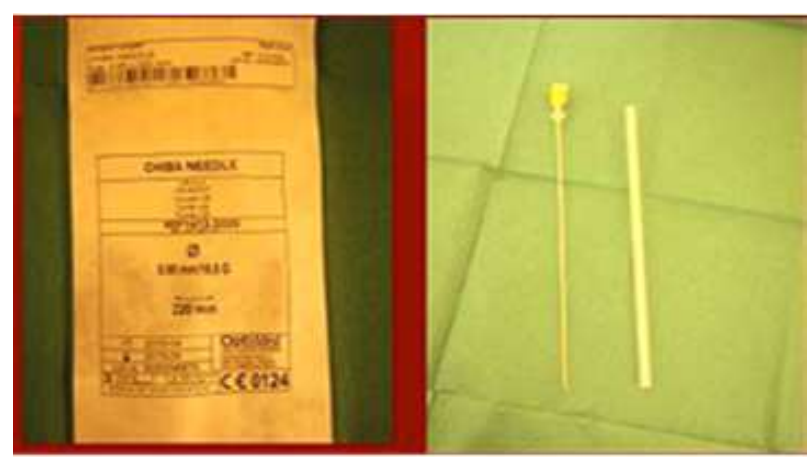

Picture 3. Needle for stem cells substrate delivery intrapulmonary.

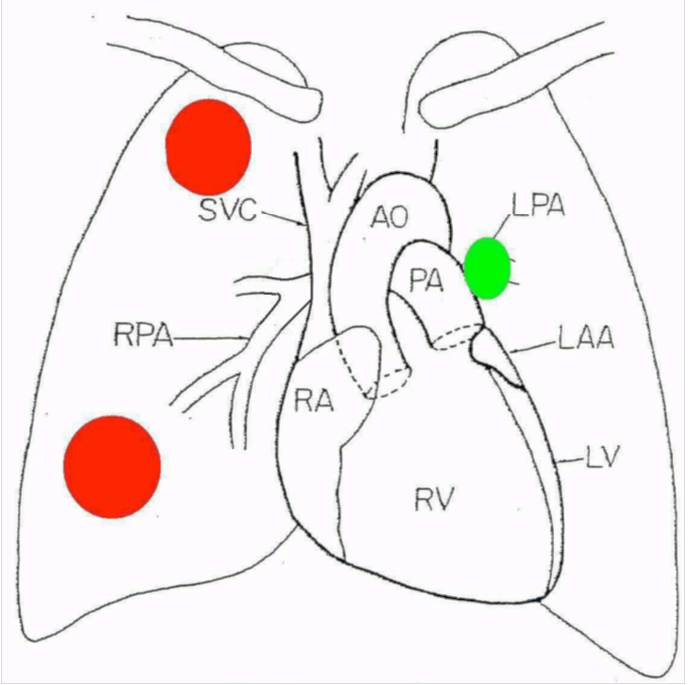

Picture 4. Schematic representation of stem cells delivery area.

Green color - stem cell transplantation in left pulmonary artery. Red color - stem cell transplantation intrapulmonary.

Bone marrow mononuclear cells were aspirated from iliac bone. Up to $35 \mathrm{ml}$ of bone marrow were aspirated from iliac bone. Mononuclear cells were isolated and enriched by gradient centrifugation and analyzed by flow cytometry.

\section{Harvest of Bone-marrow Cells}

A total up to $25 \mathrm{ml}$ (first patient) and $35 \mathrm{ml}$ (second patient) of bone marrow was aspirated into heparin-treated syringes from the iliac crest with the use of local anesthesia. The bone marrow aspirate was shipped at room temperature to the central cell-processing laboratory and diluted with sterile $0.9 \% \mathrm{NaCl}(1: 5)$, filtrated through $70 \mu \mathrm{m}$ cell strainer (BD Biosciences), and bone marrow mononuclear cells (BM-MNCs) were isolated and enriched by density gradient with the use of Ficoll-Paque Premium (GE Healthcare Ltd., manufactured according to GMP standards) according to manufacturer's instruction, with minor protocol modifications. MNCs were washed two times with $45 \mathrm{~mL} 0.9 \% \mathrm{NaCl}$ containing $10 \mathrm{U} / \mathrm{ml}$ heparin and resuspended in saline with $10000 \mathrm{U} / \mathrm{L}$ heparin. 


\section{Flow Cytometry Analysis of CD34+ Cell Content in Mononuclear Cell Fraction}

Samples for flow cytometry were taken from $15 \mathrm{~mL}$ of mononuclear cell fraction prepared for transplantation. Preparation of the isolated cells was carried out using Stem-kit ${ }^{\mathrm{TM}}$ reagents (Cat.Nr. IM3630; Beckman Coulter), that contained CD34-PE, CD45-FITC, isotype control, 7AAD (viability dye) and StemCount Fluorospheres. FACS analysis was performed on FC-500 (Beckman Coulter) using CXP analysis software. Obtained numbers of cells $/ \mu \mathrm{L}$ were calculated for total number of $\mathrm{CD} 34+$ cells within transplantation material. Measurements with less than 50,000 events were excluded from study. By using method of scintigraphy during the periods 12,14 and 27 months after stem cells implantation the evaluation of progress for neo- or revascularization was elevated and documented. Lung perfusion scintigraphy was performed after intravenous injection of 99m-Tc-MAKRO-ALBUMON (macroaggregated human albumin).

The examinations were acquired using two head gamma camera Siemens ECAM-SPECT with SPECT protocol. The matrix size $128 \times 128$, the total number of images $32-16$ with each head, time per view 30 s.

\section{Results}

Isolated mononuclear cells were resuspended in $4 \mathrm{ml}$ $0.9 \% \mathrm{NaCl}$ containing $10 \mathrm{U} / \mathrm{ml}$ heparin and released for transplantation.

\begin{tabular}{lllll}
\multicolumn{4}{c}{ Table 1. Cell extraction yield } \\
\hline Patient & Age & Sex & Biopsy vol & MNC count \\
\hline 1 & 9 & Male & $25 \mathrm{ml}$ & 35,44 \\
2 & 16 & Male & $35 \mathrm{ml}$ & 35,8 \\
\hline
\end{tabular}

Mononuclear cell suspension was applied by multiple punctures of lung tissue in radiological control.

First scintigraphy examination was preformed 24.11.2010. We can see no perfusion defects in left lung. The right lung with several perfusion defects in upper and medium lobes apical and lateral segments (see picture 5).

First follow up was done after 12 months where can see improved perfusion in intrapulmonary stem cell implantation site. There are neovascularization signs with improved perfusion in right lung (see picture 6).

Second follow up was performed after 14 months and there are positive dynamic in right lung perfusion (see picture 7).

The last examination was performed 19.02.2013. The perfusion in all previous segments is growing better - the uptake of radiopharmaceutical is improved in apical, medium lobe lateral segments. There we can see neovascularization in right lung were intrapulmonary stem cells were implanted. Red arrows show neorevascularization place. Compared with previous examination, there can see even better perfusion in all segments were transplantation of stem cells performed (see picture 8 ).

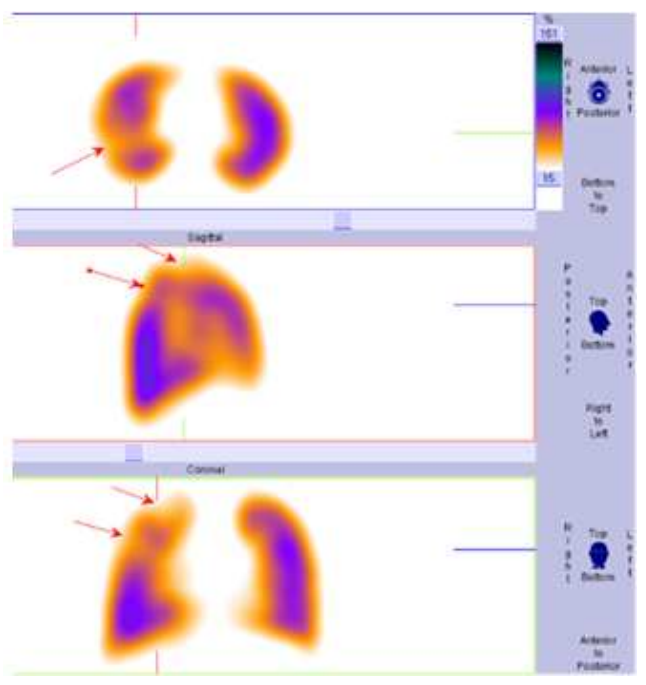

Picture 5. Scintigraphy before stem cell transplantation in 24.11.2010. No perfusion defects in left lung. The right lung with several perfusion defects in upper and medium lobes - apical and lateral segments.

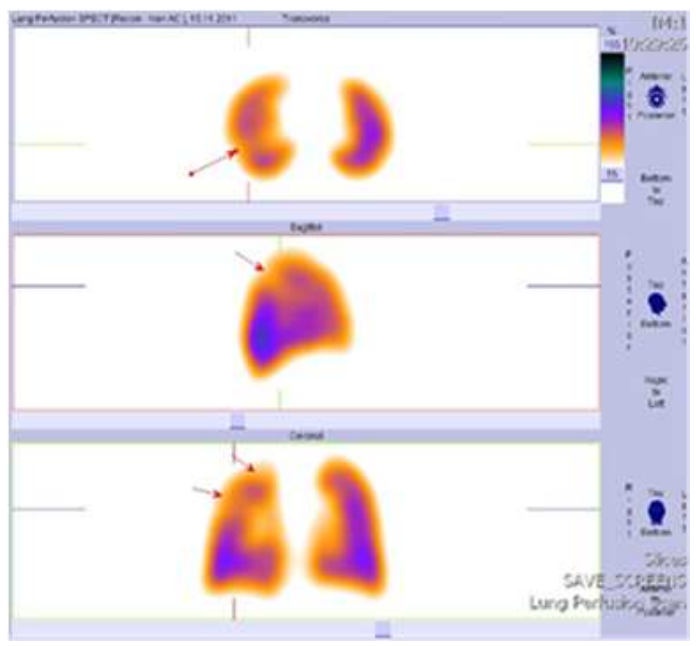

Picture 6. Neovascularization signs with improved perfusion in right lung.

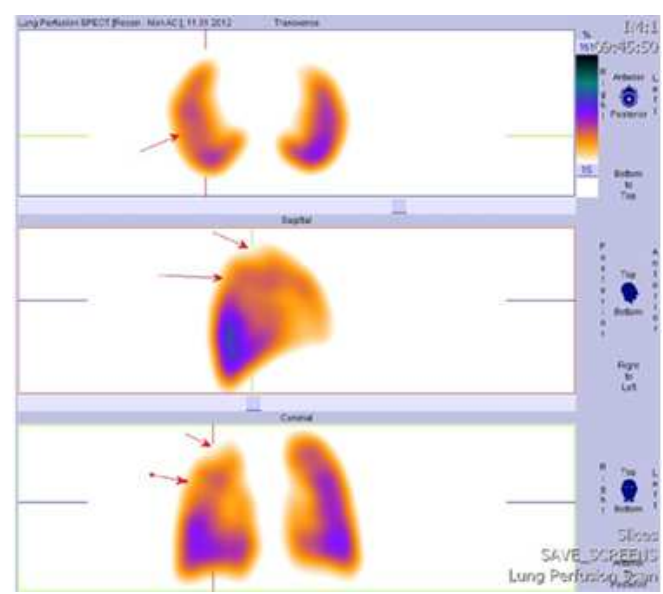

Picture 7. Positive dynamic in right lung perfusion. 


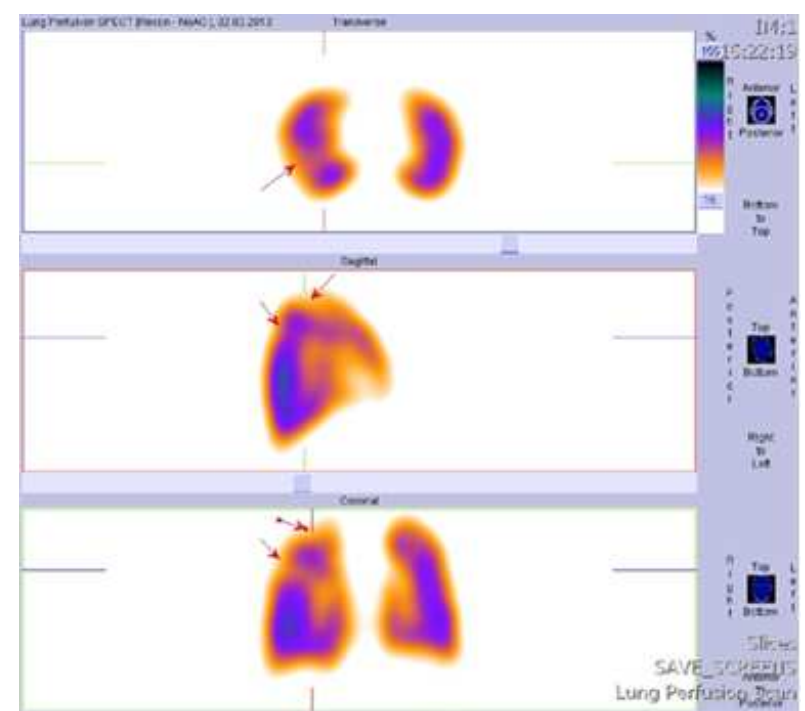

Picture 8. Better perfusion in all segments were transplantation of stem cells performed.

\section{Discussion}

In all fields of medicine the potential therapeutic benefits of stem cell transplantation are debated issue. Many investigators now believe that in adults, bone marrow-derived stem cells can be recruited to and incorporated into tissues undergoing neovascularisation [7-11]. Therefore, stem cells have been used as an alternative therapeutic strategy for ischemic cardiovascular diseases that cannot be treated by routine interventional approaches [12-15]. Recently, there has been growing interest in the therapeutic potential of using a cell-based approach to treat vasodegenerative disorders. In vascular medicine, various stem cells and adult progenitors have been highlighted as having a vasoreparative role in ischemic tissues [16].

Although recent therapeutic advances have significantly improved the prognosis for children with PAH, IPAH in children remains a devastating disease. Conventional therapy of IPAH includes nocturnal oxygen, vasodilatators, usually calcium-channel antagonists and anticoagulation. There are currently newer forms of therapy, including prostacyclin and its analogues, endothelin receptor antagonists, phosphodiesterase-5 inhibitors, and inhaled nitric oxide. Nevertheless, no define therapy exists and the long-term prognosis for these patients is poor [17]. New treatment modalities therefore are warranted to improve the patients' symptoms and survival, as a bridge to transplantation [18].

It is possible to raise an issue that intrapulmonary delivery autologous stem cells procedure could be beneficial for pathogenetic treatment for patients with severe pulmonary arterial hypertension [19, 20, 21].

Takahashi et al in 2004 perform experimental study were they examined the effects of endothelial progenitor cell (EPC) transplantation and potential benefits in dogs model with pulmonary hypertension. They find out that EPC transplantation give significant improvements in mean pulmonary artery pressure, cardiac output, and pulmonary vascular resistance. Histological evaluation revealed both improvement in the medial thickness of the small pulmonary artery and neovascularization of the lung tissue. These results indicate that EPC transplantation into the lung is effective at preventing the progression of dehydromonocrotaline-induced pulmonary hypertensive in dogs, and suggest a new therapeutic option for PPH [22].

We hypothesized that intrapulmonary delivered autologous stem cells should be motivated for neo- or revascularization of pulmonary arterial tree enlarging amount of intrapulmonary blood flow in that same time lowering blood pressure in precapillar level of pulmonary arterial blood flow. Further studies are needed to address these questions. Despite these limitations our experience with bone marrow mononuclear cell transplantation intrapulmonary in two patients with IPAH is promising and need to be studied in future.

\section{Abbreviations}

APAH - associated pulmonary arterial hypertension

EPC - endothelial progenitor cells

$\mathrm{PAH}$ - pulmonary arterial hypertension

$\mathrm{PPH}$ - primary pulmonary hypertension

IPAH - idiopathic pulmonary arterial hypertension

WHO - World Health organization

COPD - Chronic obstructive pulmonary disease

PVR - pulmonary vascular resistance

SVR - systemic vascular resistance

VSD - ventricular septal defect

SVC - superior vena cava

RPA - right pulmonary artery

$\mathrm{RA}$ - right atrium

$\mathrm{RV}$ - right ventricle

$\mathrm{AO}$ - aorta

PA - pulmonary artery

LPA - left pulmonary artery

LAA - left atrium appendage

LV - left ventricle.

\section{References}

[1] Rubin L. Primary pulmonary hypertension. N.Engl. J. Med., 1997; 336: 111-17.

[2] Galie N., Rubin L., eds. Pulmonary arterial Hypertension. Epidemiology, pathology, assessment and therapy. J.Am.Coll.Cardiol., 2004; 43: 81-90.

[3] Lammers A.F., Hislop A.A., Flynn Y. et al. Epoprostenol treatment in children with severe pulmonary hypertension. Heart, 2007; 93: 739-43.

[4] Maiya S., Hislop A.A, Flynn Y., et al. Response to bosentan in children with pulmonary hypertension. Heart, 2006; 92:664-70. 
[5] Haworth S., Flynn Y., Hislop A.A. Survival and quality of life in children with severe pulmonary hypertension. Heart, 2006;92: (Suppl. II): A14.

[6] Hislop A.A., Flynn Y., Haworth S.G. Summary of the experiences of the UK pulmonary hypertension service for children 2001 - 2005. Proceedings of the American Thoracic Society, 2006; 3: A57.

[7] Suri C., Jones P., F., Patan S., et al. Requisite role of angiothensin-1, a ligand for the TIE2 receptor, during embryonic angiogenesis. Cell, 1996; 87: 1171-80 (Pub.Med, 8980224).

[8] Assmus B., Schächinger V., Teupe C., et al. Transplantation of progenitor cells and regeneration enhancement in acute myocardial infarction (TOPCARE-AMI). Circulation, 2002; 106: 3009-17 (Pub. Med.: 12473544).

[9] Britten M.B., Abdolmeali N.D., Assmus B. et al. Infarct remodeling after intracoronary progenitor cell treatment in patients with acute myocardial infarction (TOPCARE-AMI) mechanistic insights from serial contrast - enhanced magnetic resonance imaging. Circulation, 2003; 108 -: 2012 - 8 (Pub. Med. 14557356).

[10] Schächinger V., Assmus B., Britten M.B., et al. Transplantation of progenitor cells and regeneration enhancement in acute myocardial infarction - final one-year results of the TOPCARE-AMI trial. J.Am.Coll.Cardiol., 2004:44:1690-9

[11] Yifn Zhou, Suna Wand Kerth A. Horvath. Direct injection of autologous mesenchymal stromal cells improves myocardial function. Biochem. Biophs, Rec. Sommun., 2009; 18: 390 (3) 902-907.

[12] Strauer B.E. Brehm M., Zeus T et al. Regeneration of human infracted heart muscle by intracoronary mononuclear bone marrow cell transplantation in humans. Circulation, 2002; 106: 1913-18.

[13] Perin E.C. Dahmann H.F.R. Borojevic R. et al. Transendocardial autologous bone marrow cell transplantation for severe chronic ischemic heart failure. Circulation, 2003; 107: 2294-302.

[14] Fuchs S., Satler L.F. Koronovski R. et al. Catheter-based autologous bone marrow myocardial injection in no-option patients with advanced coronary artery disease - a feasibility study. J. Am. Coll. Cardiol. 2003; 41:1721-4.

[15] Lācis A., Ērglis A. Intramyocardial administration of autologous bone marrow mononuclear cells in a critically ill child with dilated cardiomyopathy. Cardiology in the Young, 2011; 21: 110-112.

[16] Christina L O'Neill, Michelle T O'Doherty, Sarah EJ Wilson, Amer A Rana, Claire E Hirst, Alan W Stitt and Reinhold J Medina. Therapeutic revascularisation of ischemic tissue: the opportunities and challenges for therapy using vascular stem/progenitor cells. Stem Cell Research \& Therapy 2012, $3: 31$.

[17] Clabby ML., Canter CE., Moller JH., Bridges ND., Hemodynamic data and survival in children with pulmonary hypertension. J. Am. Coll. Cardiol. 1997; 30: 554-560.

[18] Zhu JH., Wang XX., Zhang FR., Shang YP et al. Safety and efficacy of autologous endothelial progenitor cells transplantation in children with idiopathic pulmonary arterial hypertension: Open-Label pilot study. Pediatr. Transplantation 2008; 12: 650-655.

[19] T. Kinnaird, E. Stabile, M.S. Burnett, C.W. Lee, S. Barr, S. Fuchs, S.E. Epstein. Marrow-Derived Stromal Cells Express Genes Encoding a Broad Spectrum of Arteriogenic Cytokines and Promote In Vitro and In Vivo Arteriogenesis Through Paracrine Mechanisms. Circulation Research. 2004; 94: 678-685.

[20] T. Kinnaird, MBBCh; E. Stabile, MD; M.S. Burnett, PhD; M. Shou, MD; C.W. Lee, MD; S. Barr, MBBCh; S. Fuchs, MD; S.E. Epstein, MDLocal Delivery of Marrow-Derived Stromal Cells Augments Collateral Perfusion Through Paracrine Mechanisms. Circulation. 2004; 109: 1543-1549.

[21] Gnecehi M, Mirotsu M, Dzun V.J. Stem cell therapy for heart repair. The paracrine paradigm in "Heart regeneration". Max Planck Institute for heart and lung research, Germany. World scientific Publishing, Co. Ptc. Ltd. Copyright@2012.pp 219-245

[22] Takahashi M, Nakamura T, Toba T, Kajiwara N, Kato H, Shimizu Y. Transplantation of endothelial progenitor cells into the lung to alleviate pulmonary hypertension in dogs. Tissue Eng. 2004 May-Jun; 10 (5-6): 771-9. 